\title{
Development and validation of a novel lipid metabolism-related gene prognostic signature and candidate drugs for patients with bladder cancer
}

Ke Zhu ${ }^{1,2+}$, Liu Xiaogiang ${ }^{1,2+}$, Wen Deng ${ }^{1}$, Gongxian Wang ${ }^{1,2^{*}}$ and Bin $\mathrm{Fu}^{1,2^{*}}$ (D)

\begin{abstract}
Background: Bladder cancer (BLCA) is a common cancer associated with an unfavorable prognosis. Increasing numbers of studies have demonstrated that lipid metabolism affects the progression and treatment of tumors. Therefore, this study aimed to explore the function and prognostic value of lipid metabolism-related genes in patients with bladder cancer.

Methods: Lipid metabolism-related genes (LRGs) were acquired from the Molecular Signature Database (MSigDB). LRG mRNA expression and patient clinical data were obtained from The Cancer Genome Atlas (TCGA) and Gene Expression Omnibus (GEO) datasets. Cox regression analysis and least absolute shrinkage and selection operator (LASSO) regression analysis was used to construct a signature for predicting overall survival of patients with BLCA. Kaplan-Meier analysis was performed to assess prognosis. The connectivity Map (CMAP) database was used to identify small molecule drugs for treatment. A nomogram was constructed and assessed by combining the signature and other clinical factors. The CIBERSORT, MCPcounter, QUANTISEQ, XCELL, CIBERSORT-ABS, TIMER and EPIC algorithms were used to analyze the immunological characteristics.

Results: An 11-LRG signature was successfully constructed and validated to predict the prognosis of BLCA patients. Furthermore, we also found that the 11-gene signature was an independent hazardous factor. Functional analysis suggested that the LRGs were closely related to the PPAR signaling pathway, fatty acid metabolism and AMPK signaling pathway. The prognostic model was closely related to immune cell infiltration. Moreover, the expression of key immune checkpoint genes (PD1, CTLA4, PD-L1, LAG3, and HAVCR2) was higher in patients in the high-risk group than in those in the low-risk group. The prognostic signature based on 11-LRGs exhibited better performance in predicting overall survival than conventional clinical characteristics. Five small molecule drugs could be candidate drug treatments for BLCA patients based on the CMAP dataset.
\end{abstract}

\footnotetext{
* Correspondence: wanggx-mr@126.com; urofubin@sina.com

${ }^{\dagger}$ Ke Zhu and Liu Xiaoqiang contributed equally to this work.

'Present address: Department of Urology, The First Affiliated Hospital of

Nanchang University, 17 Yongwaizheng Street, Jiangxi 330006 Nanchang,

People's Republic of China

Full list of author information is available at the end of the article
}

\section{$\triangle B M C$}

(C) The Author(s). 2021 Open Access This article is licensed under a Creative Commons Attribution 4.0 International License, which permits use, sharing, adaptation, distribution and reproduction in any medium or format, as long as you give appropriate credit to the original author(s) and the source, provide a link to the Creative Commons licence, and indicate if changes were made. The images or other third party material in this article are included in the article's Creative Commons licence, unless indicated otherwise in a credit line to the material. If material is not included in the article's Creative Commons licence and your intended use is not permitted by statutory regulation or exceeds the permitted use, you will need to obtain permission directly from the copyright holder. To view a copy of this licence, visit http://creativecommons.org/licenses/by/4.0/ The Creative Commons Public Domain Dedication waiver (http://creativecommons.org/publicdomain/zero/1.0/) applies to the data made available in this article, unless otherwise stated in a credit line to the data. 
Conclusions: In conclusion, the current study identified a reliable signature based on 11-LRGs for predicting the prognosis and response to immunotherapy in patients with BLCA. Five small molecule drugs were identified for the treatments of BLCA patients.

Keywords: Bladder cancer, Lipid metabolism, Signature, TCGA, GEO, Biomarker, Prognosis, Immune

\section{Introduction}

Bladder cancer (BLCA) is one of the most common malignancies of the genitourinary system, and it is also the 12th most common cancer worldwide [1]. The incident risk of BLCA is closely correlated with smoking [2]. Based on muscular invasion, BLCA can be classified into two types: non-muscle-invasive BLCA and muscleinvasive BLCA. The former is generally treated with transurethral bladder tumor resection (TURBT) and regular intravesical instillation. However, this type of BLCA easily recurs and progresses. The latter usually requires radical cystectomy and urinary diversion, even chemotherapy, immunotherapy, and targeted therapies. Moreover, patient prognosis may remain unfavorable.Therefore, it is essential to identify early diagnostic and prognostic biomarkers to improve the curative effects of BLCA.

Emerging evidence has confirmed that aberrant metabolic reprogramming, especially glycolysis [3, 4], mitochondrial oxidative phosphorylation $[5,6]$, cholesterol metabolic pathways [7], and fatty acid metabolism [8], contributes to the occurrence of many diseases, including cancers and inflammation [9]. Lipids are not only one of the three nutrient types necessary for normal cell growth but also components of cell membranes, and these roles determine the significant effect of lipids on cell growth and homeostasis. Recently, lipid metabolism disorder has been regarded as one of the most significant metabolic hallmarks of tumor cells $[10,11]$. Lipids not only provide nutrition for the malignant proliferation of tumor cells but also can favor tumor cells adaptation to microenvironmental changes. Bladder carcinogenesis is associated with alterations in lipid metabolism [12-14]. Overexpression of fatty acid synthase (FASN) has been found to be negatively correlated with OS and recurrence [15]. Furthermore, silencing FASN expression significantly suppressed the proliferation and invasion of BLCA cells through the AKT/ mTOR signaling pathway [16]. FASN might contribute to chemotherapy resistance [17].

In the present study, the expression and potential functions of lipid metabolism-related genes in BLCA systematically analyzed by a series of bioinformatic methods. Then, five small molecule compounds that target lipid metabolism related genes were identified for BLCA treatment. Finally, a prognostic signature based on eleven lipid metabolism-related genes that can accurately predict BLCA patient prognosis was constructed and validated. Furthermore, the prognostic signature was an independent prognostic indicator and that was correlated with immune cell infiltration. All these results indicated that lipid metabolism may be a promising treatment direction for BLCA.

\section{Materials and methods \\ TCGA-BLCA cohort and GEO cohort}

The level-three transcriptome RNA sequencing data and the corresponding clinicopathological characteristics of bladder cancer patients were downloaded from The Cancer Genome Atlas (TCGA) data portal (https://gdcportal.nci.nih.gov/). Moreover, GSE13507 was obtained from the Illumina Human-6 v2.0 Expression BeadChip platform in Gene Expression Omnibus (GEO) database (https://www.ncbi.nlm.nih.gov/geo/) and used as a validation set.

\section{Lipid metabolism gene set}

Four lipid metabolism datasets (Reactome metabolism of lipids, Reactome phospholipid metabolism, Hallmark fatty acid metabolism, and Kyoto Encyclopedia of Genes and Genomes (KEGG) glycerophospholipid metabolism) were acquired from the Molecular Signature Database v7.1 (MSigDB; https://www.gsea-msigdb.org/gsea/ msigdb).

\section{Identification of differentially expressed lipid metabolism- related genes}

The Limma package of $\mathrm{R}$ (version $\mathrm{R}$ 3.6.1, https:// bioconductor.org/packages/release/bioc/) was used to screen the differentially expressed lipid metabolismrelated genes (DELRGs) between the BLCA and normal samples. A false discovery rate $(\mathrm{FDR})<0.05$ and $\mid \log 2$-fold change $(\mathrm{FC}) \mid>1$ were set as the cutoff criteria.

\section{Enrichment analysis of DELRGs}

To further investigate the potential molecular mechanisms in which the DELRGs were involved, Gene Ontology (GO) and pathway enrichment analyses of the DELR Gs were performed with the clusterProfiler R package. $P$ and FDR values $<0.05$ were considered statistically significant. 
Protein-protein interaction (PPI) network construction DELRGs were submitted to the STRING database (http://www.string-db.org/, version 11.0) to acquire PPI information and visualized by Cytoscape (version 3.8.2).

\section{Identification of potential small molecule drugs}

The connectivity Map (CMAP) database (http://www. broadinstitute.org) was used to predict potential drugs that may reverse or induce the biological states of BLCA based on the DELRGs. The DELRGs was submitted to the CMAP database to search small molecular drugs that could be used for BLCA treatment. The enrichment scores ranged from -1 to 1 . A negative score suggested that the drug could be beneficial for BLCA treatment.

\section{Construction and validation of LRG prognostic signature} Univariate Cox regression was used to identify the prognostic value of LRGs in BLCA. Then, LASSO regression analysis was conducted to select potential risk genes and eliminate genes that would overfit the model. Finally, multivariate Cox regression analysis was performed to establish an optimized risk score model. Risk scores was calculated by the following formula:

$$
\begin{aligned}
\text { Risk score }= & (\text { Coef } 1 * \text { expression mRNA } 1) \\
& +(\text { Coef } 2 * \text { expression RNA } 2) \\
& +(\text { Coef } \mathrm{n} * \text { expression mRNA } \mathrm{n})
\end{aligned}
$$

where Coef was Cox regression model coefficient of relevant mRNA. Patients with ccRCC were classified into two groups (low-risk groups and high-risk groups) on the basis of median risk score. Kaplan-Meier curves were plotted to evaluate the significant difference in survival outcomes between the high risk and low risk groups. Principal component analysis (PCA) and t-distributed stochastic neighbor embedding ( $t$-SNE) were used to analyze the dimensionality reduction. The survival ROC package was used to construct the receiver operating characteristic curve (ROC). The prognostic model was externally validated using the GEO dataset to test its stability.

\section{Construction of a nomogram}

Univariate and multivariate Cox regression analyses were conducted to determine if the predictive effect of the LRG prognostic signature was independent of clinical variables. A nomogram survival model was established using the $\mathrm{R}$ package rms based on the independent prognosis-associated LRGs to predict the survival rate of BLCA patients at 3 and 5 years. The nomogram and calibration curve were plotted with the "rms" $\mathrm{R}$ package. The accuracy of the nomogram was estimated by calculating the consistency index between the actual observation frequency and the predicted probability. A calibration curve was utilized to visualize the performance of the nomogram.

\section{Immune cells infiltration}

The CIBERSORT, MCPcounter, QUANTISEQ, XCELL, CIBERSORT-ABS, TIMER and EPIC algorithms were used to analyze the immunological characteristics of the high-risk groups and low-risk groups. To predict the effect of immune checkpoint blockade therapy, we also explored the expression of key immune checkpoint genes including PDCD1, LAG3, HAVCR2, PD-L1 and CTLA4 in the groups.

\section{Validation of protein expressions of 11 LRGs}

The Human Protein Atlas (HPA, https://www. proteinatlas.org/) database was conducted to validate the protein expression of 11 LRGs between BLCA tissues and normal bladder tissues via using immunohistochemistry (IHC) from HPA database.

\section{Statistical analysis}

All the statistical analyses were conducted with $\mathrm{R}$ software (Version 3.5.0). $P<0.05$ was served as the cutoff criterion.

\section{Results}

\section{Identification of DELRGs in BLCA}

The RNA-seq data of 857 LRGs between BLCA tissues $(n=414)$ and normal bladder tissues $(n=19)$ were acquired from TCGA dataset. 113 DELRGs were identified with FDR $<0.05$ and $|\log 2 \mathrm{FC}|>1$ as the screening criteria, including 49 downregulated and 64 upregulated genes. The heatmap of the DELRGs between the BLCA tissues and normal bladder tissues was displayed in Fig. 1.

\section{Functional enrichment analysis of DELRGs}

To further clarify the potential mechanisms of DELR Gs, functional enrichment analysis was performed with the 113 DELRGs. In the biological processes (Fig. 2A), the DELRGs were mainly enriched in steroid metabolic process, fatty acid metabolic process, lipid catabolic process, steroid biosynthetic process, and fatty acid derivative metabolic process. In the cellular components (Fig. 2A), the DELRGs were mainly enriched in lipid droplet, peroxisomal matrix, myelin sheath, microbody lumen, peroxisome, and microbody. In the molecular functions (Fig. 2A), the DELR Gs were mainly enriched in cofactor binding, monooxygenase activity, iron ion binding, phospholipase A2 


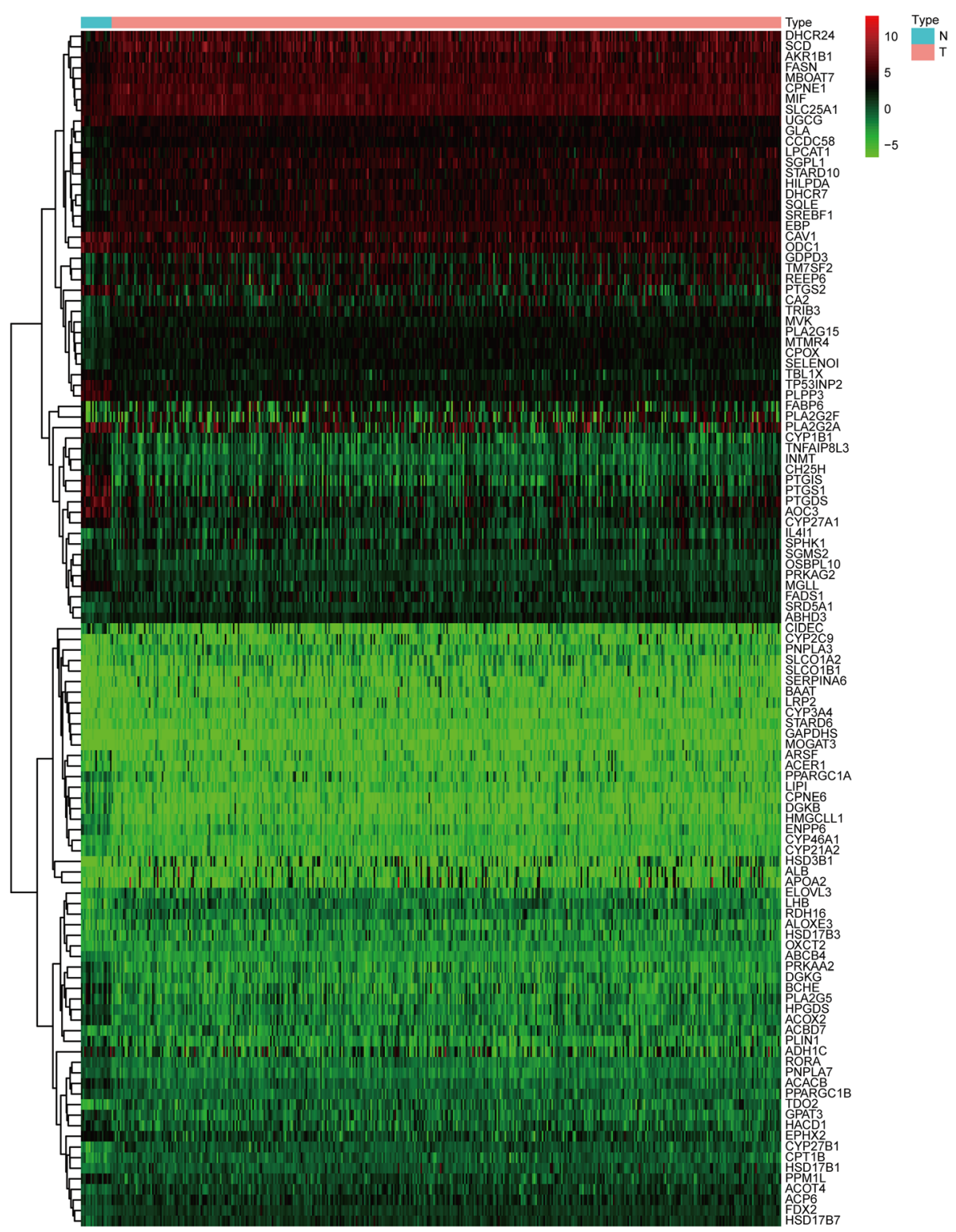

Fig. 1 Heatmap showed differentially expressed LRGs

activity, and NADP binding. In the KEGG pathways, the results showed that the DELRGs were mainly enriched in glycerophospholipid metabolism, PPAR signaling pathway, fatty acid metabolism, and AMPK signaling pathway (Fig. 2B). All these results indicated that lipid metabolism might be implicated in the development of BLCA.

\section{PPI network}

To investigate the association of the DELRGs, a PPI network of the DELRGs was established comprising 95 nodes and 350 edges and visualized via Cytoscape (Fig. 3).

\section{Small molecular drugs}

To identify candidate small molecular drugs for treating BLCA, all the DELRGs were divided into upregulated and downregulated groups, which were uploaded to the CMAP database. Five small molecular drugs with anticancer effects on BLCA progression were identified (enrichment score $<0)$ with $P<0.01$ and $n>2$ as the screening criteria. The 5 small molecule drugs were flurbiprofen, meclizine, alfuzosin, ethotoin, and fenoprofen (Table 1).

\section{Construction of LRGs signature for predicting OS}

Based on the 113 DELRGs, Cox and LASSO regression analyses were conducted to select prognostic genes in 


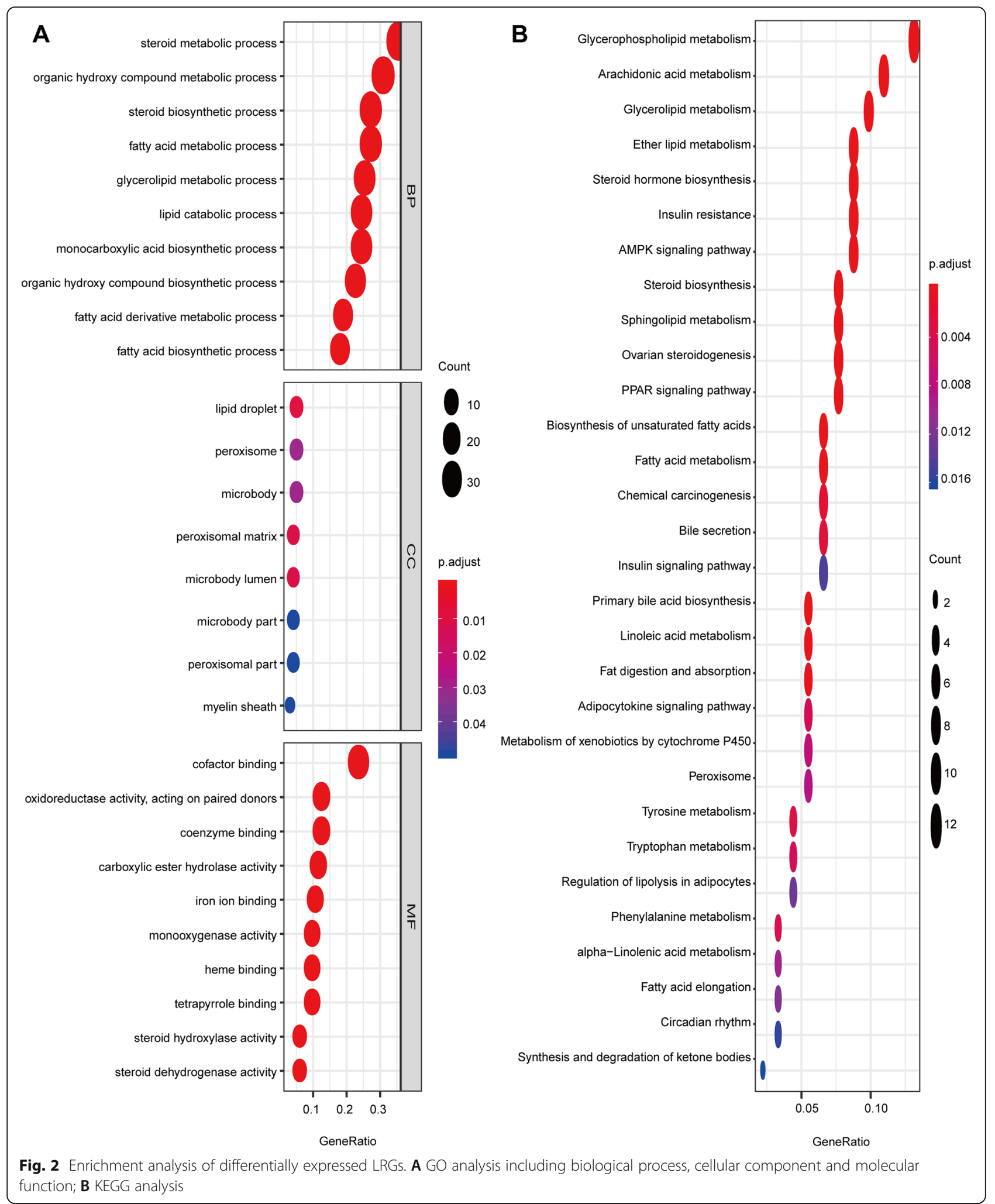




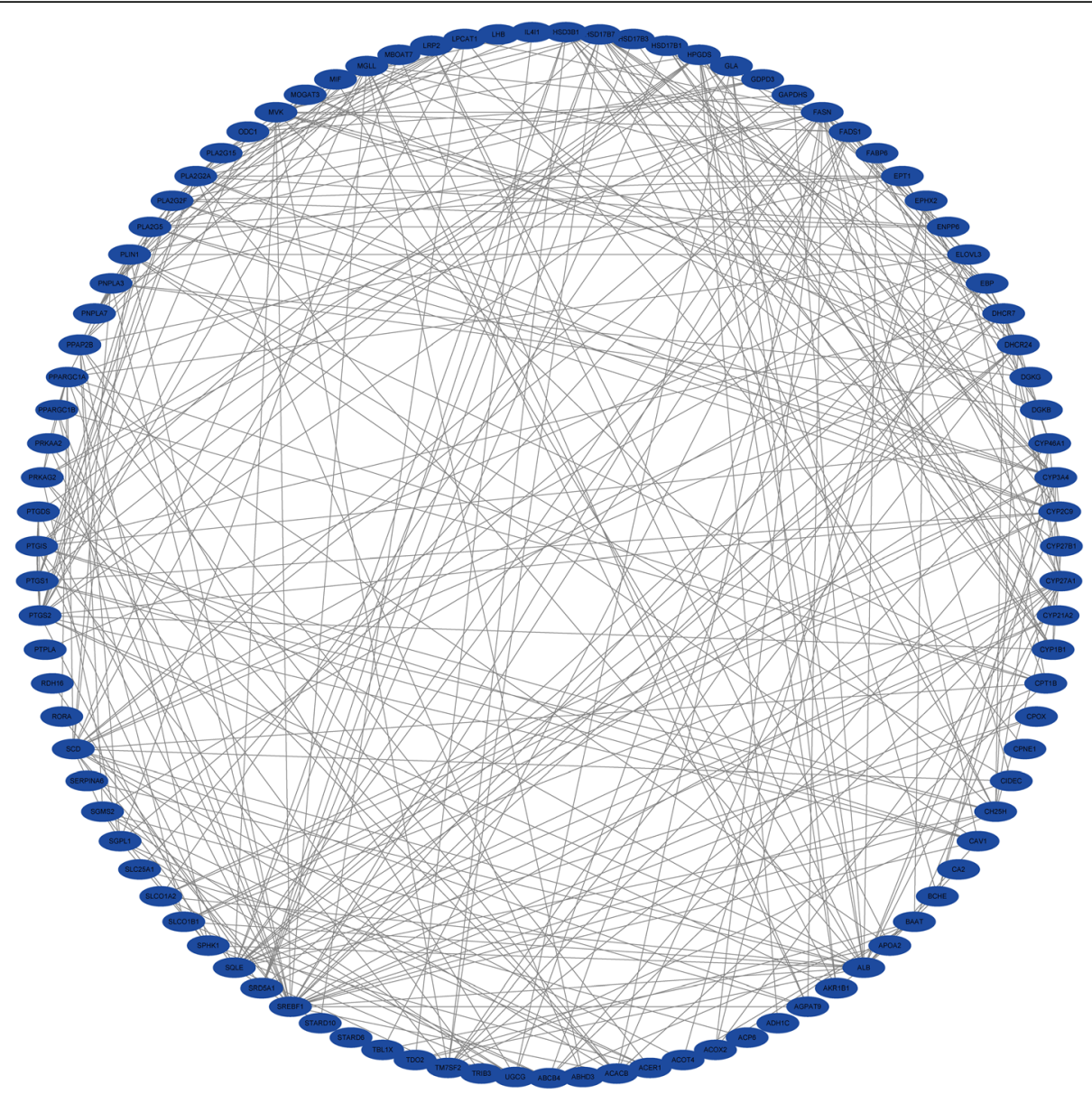

Fig. 3 Protein-protein interaction (PPI) network of differentially expressed LRGs

the TCGA dataset. First, twenty-nine DELRGs were associated with the prognosis of BLCA patients according to univariate Cox regression analysis (Fig. 4A). Then, to ensure the stability and feasibility of clinical prognosis based on these 29 genes, we obtained 19 DELRGs associated with the prognosis of BLCA patients by LASSO analysis (Fig. 4B and $\mathrm{C}$ ). Finally, after multivariate Cox regression analysis, 11 genes, including FASN, MBOAT7, SERPINA6, PPAR GC1B, FADS1, CPT1B, HSD17B1, OSBPL10, AKR1B1, CCDC58, and PLA2G2F, were identified and used to construct a prognostic signature for OS (Table 2). We

Table 1 The 5 small molecule drugs of CMP dataset

\begin{tabular}{lllll}
\hline Names of drugs & Enrichment & $\boldsymbol{p}$ value & $\mathbf{n}$ & Percent non-null \\
\hline flurbiprofen & -0.947 & 0.00026 & 3 & $100 \%$ \\
meclozine & -0.911 & 0.00124 & 3 & $100 \%$ \\
alfuzosin & -0.894 & 0.00226 & 3 & $100 \%$ \\
ethotoin & -0.893 & 0.00234 & 3 & $100 \%$ \\
fenoprofen & -0.848 & 0.00699 & 3 & $100 \%$ \\
\hline
\end{tabular}

developed an 11 gene signature-based risk score based on their cox coefficient as follows:

$$
\begin{aligned}
\text { Risk score }= & (0.2728 \times \text { FASN expression }) \\
& +(-0.2101 \times \text { MBOAT7 expression }) \\
& +(0.8956 \times \text { SERPINA6 expression }) \\
& +(-0.3559 \\
& \times \text { PPARGC1B expression }) \\
& +(0.1154 \times \text { FADS1 expression }) \\
& +(-0.2844 \times \text { CPT1B expression }) \\
& +(0.1872 \times \text { HSD17B1 expression }) \\
& +(0.193 \times \text { OSBPL10 expression }) \\
& +(0.1156 \times \text { AKR1B1 expression }) \\
& +(-0.2434 \times \text { CCDC58 expression }) \\
& +(0.064 \times \text { PLA2G2F expression })
\end{aligned}
$$

Patients were then divided into high- and low-risk groups on the basis of the median value. PCA and t-SNE analysis indicated distinct dimensions among different groups (Fig. 7A and C). Patients in the high-risk group showed poorer prognosis than those in the low-risk group $(P<$ 0.05 ) (Fig. 5A and C). Time-dependent ROC analysis 
A

$\begin{array}{lrr} & \text { pvalue } & \text { Hazard ratio } \\ \text { FASN } & 0.003 & 1.253(1.078-1.458) \\ \text { SGPL1 } & 0.047 & 0.835(0.699-0.998) \\ \text { BCHE } & 0.032 & 1.188(1.015-1.390) \\ \text { FABP6 } & 0.008 & 0.892(0.819-0.971) \\ \text { TNFAIP8L3 } & 0.003 & 1.271(1.087-1.486) \\ \text { MBOAT7 } & 0.015 & 0.798(0.665-0.957) \\ \text { SREBF1 } & 0.044 & 1.163(1.004-1.346) \\ \text { SERPINA6 } & 0.013 & 0.251(0.085-0.744) \\ \text { GPAT3 } & 0.017 & 1.220(1.037-1.436) \\ \text { ACP6 } & 0.004 & 0.772(0.648-0.919) \\ \text { CAV1 } & 0.013 & 1.117(1.024-1.218) \\ \text { CYP1B1 } & 0.014 & 1.128(1.025-1.241) \\ \text { PPARGC1B } & 0.029 & 0.674(0.473-0.961) \\ \text { SGMS2 } & 0.033 & 1.246(1.018-1.524) \\ \text { FADS1 } & 0.001 & 1.238(1.090-1.407) \\ \text { TRIB3 } & 0.005 & 1.206(1.058-1.375) \\ \text { CPT1B } & <0.001 & 0.558(0.408-0.763) \\ \text { DHCR24 } & 0.041 & 1.123(1.005-1.255) \\ \text { HSD17B1 } & 0.027 & 1.183(1.019-1.373) \\ \text { OSBPL10 } & 0.001 & 1.432(1.154-1.775) \\ \text { CYP2C9 } & 0.049 & 0.744(0.554-0.999) \\ \text { SQLE } & 0.026 & 1.192(1.021-1.392) \\ \text { AKR1B1 } & 0.004 & 1.172(1.052-1.305) \\ \text { PTGIS } & 0.007 & 1.124(1.033-1.223) \\ \text { ACER1 } & 0.043 & 1.704(1.016-2.860) \\ \text { SCDC58 } & 0.036 & 0.729(0.542-0.979) \\ \text { SPHK1 } & 0.009 & 1.147(1.035-1.272) \\ & 0.004 & 0.902(0.840-0.968) \\ \text { PLAF } & & 1.151(1.039-1.276) \\ \text { A } & & \end{array}$

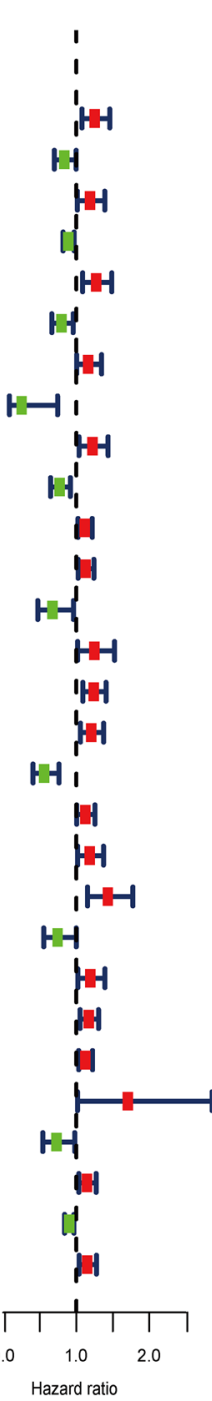

B

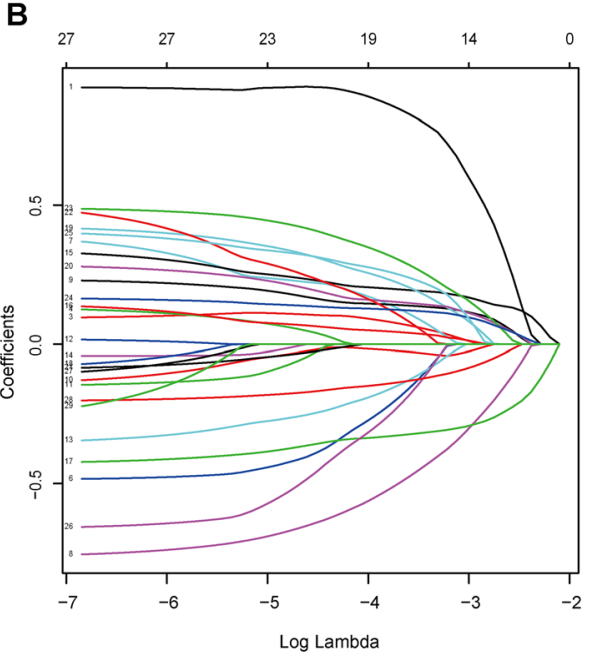

$\begin{array}{llllllllllllllll}\text { C } & 27 & 27 & 27 & 27 & 26 & 23 & 22 & 21 & 19 & 19 & 16 & 10 & 7 & 2\end{array}$

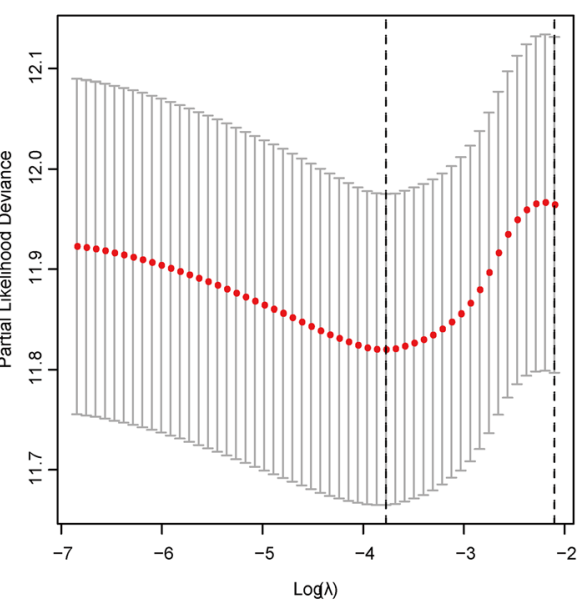

Fig. 4 Identification of DELRGs closely related to prognosis. A Identification of differentially expressed LRGs by univariate Cox regression analysis. B The coefficient profile of 19 prognostic genes by Lasso regression analysis. C Tenfold cross-validation for tuning parameter selection in the LASSO analysis

Table.2 The multivariate Cox regression analysis of11 prognostic genes in bladder cancer

\begin{tabular}{lllll}
\hline Gene names & HR & $\mathbf{9 5 \%} \mathbf{C l}$ & Coef & $\boldsymbol{p}$-value \\
\hline FASN & 1.314 & $1.114-1.549$ & 0.2728 & 0.001 \\
MBOA7 & 0.811 & $0.661-0.994$ & -0.2101 & 0.043 \\
SERPINA6 & 0.408 & $0.146-1.141$ & 0.8956 & 0.088 \\
PPARGC1B & 0.701 & $0.486-1.01$ & -0.3559 & 0.057 \\
FADS1 & 1.122 & $0.962-1.31$ & 0.1154 & 0.143 \\
HSD17B1 & 1.206 & $1.027-1.416$ & 0.1872 & 0.022 \\
AKR1B1 & 1.123 & $0.997-1.264$ & 0.1156 & 0.057 \\
PLA2G2F & 0.938 & $0.861-1.022$ & 0.064 & 0.142 \\
CCDC58 & 0.784 & $0.563-1.091$ & -0.2434 & 0.149 \\
CPT1B & 0.752 & $0.532-1.064$ & -0.2844 & 0.107 \\
OSBPL10 & 1.213 & $0.946-1.555$ & 0.193 & 0.128 \\
\hline
\end{tabular}

indicated that the prognostic accuracy of the 11 LRG signature in the TCGA set was 0.716 at 5 years (Fig. 5B).

\section{Validation of the LRGs signature in GEO dataset}

To ensure the prediction value of the LRG signature, GSE13507 was served as a validation set to validate our results. According to the LRG-based classifier identified above, the BLCA patients in the validation sets were divided into a high- and a low-risk group by the median risk score. In accord with the results above, significantly higher survival rates were observed in the low-risk group than in the high-risk group in the validation set (Fig. 6A and C). PCA and t-SNE analyses also indicated distinct dimensions among different groups (Fig. 7B and D). Timedependent ROC analysis indicated that the prognostic accuracy of the LRG signature was 0.721 at 5 years (Fig. 6B). 


\section{A}
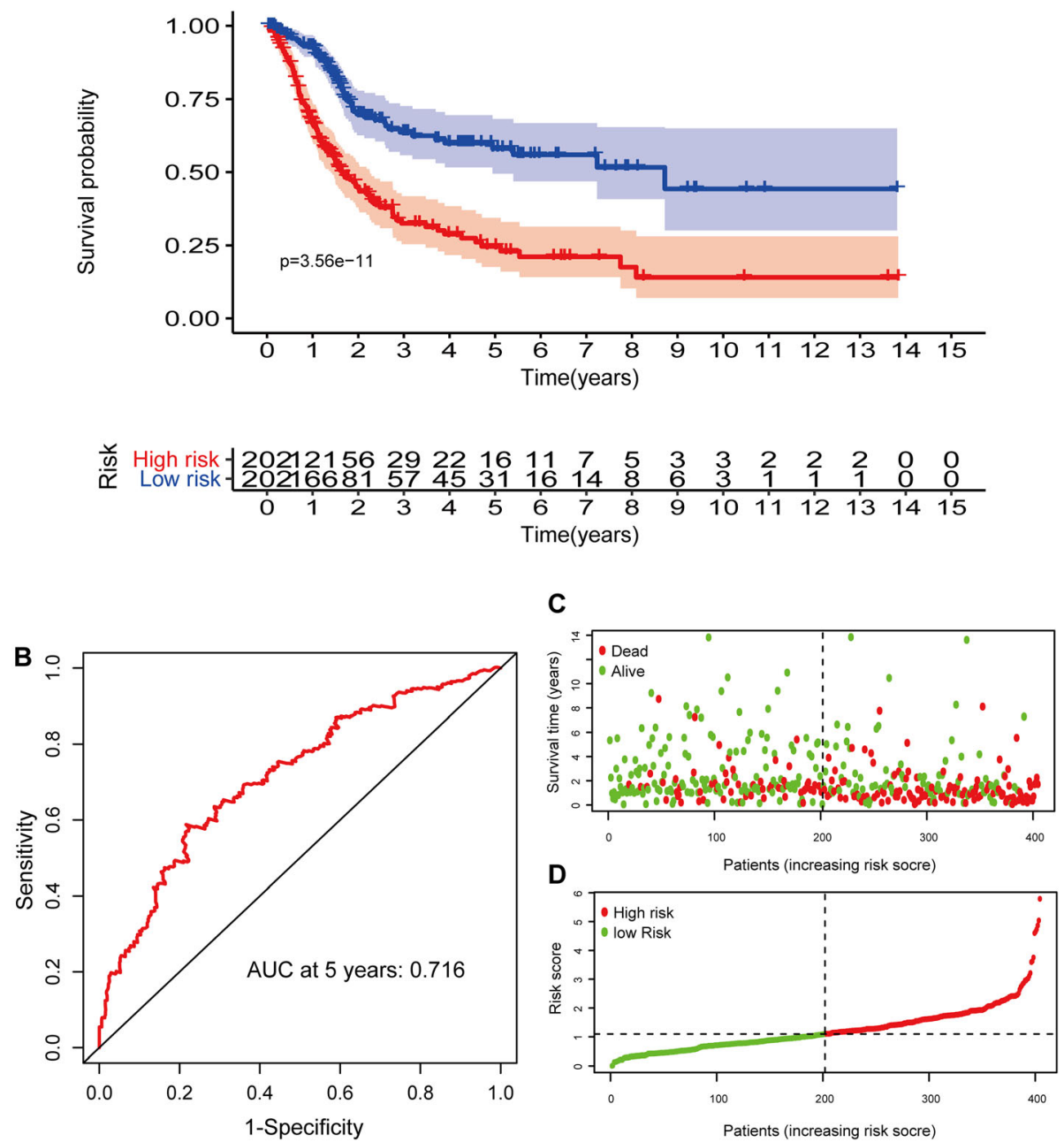

Fig. 5 Construction of a prognostic signature based on 11 LRGs in TCGA set. A Kaplan-Meier survival analysis of BLCA patients between high-risk groups and low-risk groups. B Time-independent receiver operating characteristic (ROC) analysis of risk scores predicting the overall survival. C Distribution of LRG-based risk score and different patterns of survival status and survival time between the high- and low-risk groups

\section{The relationship between risk scores and clinical characteristics}

To further explore the correlation between risk scores and clinical characteristics, we analyzed the differences of the risk scores in the various subgroups stratified by clinical characteristics. The results indicated that the risk scores were closely related to clinical characteristics and significantly elevated in subgroups of high pathological grade, $\mathrm{T}$ stage (T3 and T4), N stage (N1-N2-N3), and TNM stage (Stage III and Stage IV) (Fig. 8A and B). However, the risk score in the age or gender subgroups was not statistically different. Subsequently, we further investigated the prognostic value of the LRG signature stratified by age ( $>65$ years or $\leq 65$ years), TNM stage (I + II or III + IV), pathological grade (high), $\mathrm{T}$ stage (T1-T2 or T3- T4), gender (female or male), and N stage (N0 or N1-N2-N3). The
Kaplan-Meier analysis suggested that patients with high risk scores had worse outcomes than those with low-risk scores in all the subgroups such as male or female, age (> 65 years) or ( $<=65$ years), $\mathrm{T}$ stage (T1-T2) or (T3-T4), $\mathrm{N}$ stage (N0) or (N1-N2-N3), pathological grade (high) and TNM stage (Stage I-II) or (Stage III-IV) (all $P<0.05$ ), these results suggested that risk scores might serve as an effective indicator for predicting the over survival of patients with BLCA (Fig. 9).

\section{Independent prognostic role of LRGs signature}

Univariate and multivariate Cox regression analyses were performed to explore the independence of the LRG signature by comparing the clinical features including gender, age, grade, TNM stage, $\mathrm{T}$ stage, and $\mathrm{N}$ stage. Age $(\mathrm{HR}=$ $1.037,95 \% \mathrm{CI}=1.020-1.055 ; P<0.001)$, TNM stage $(\mathrm{HR}=$ 


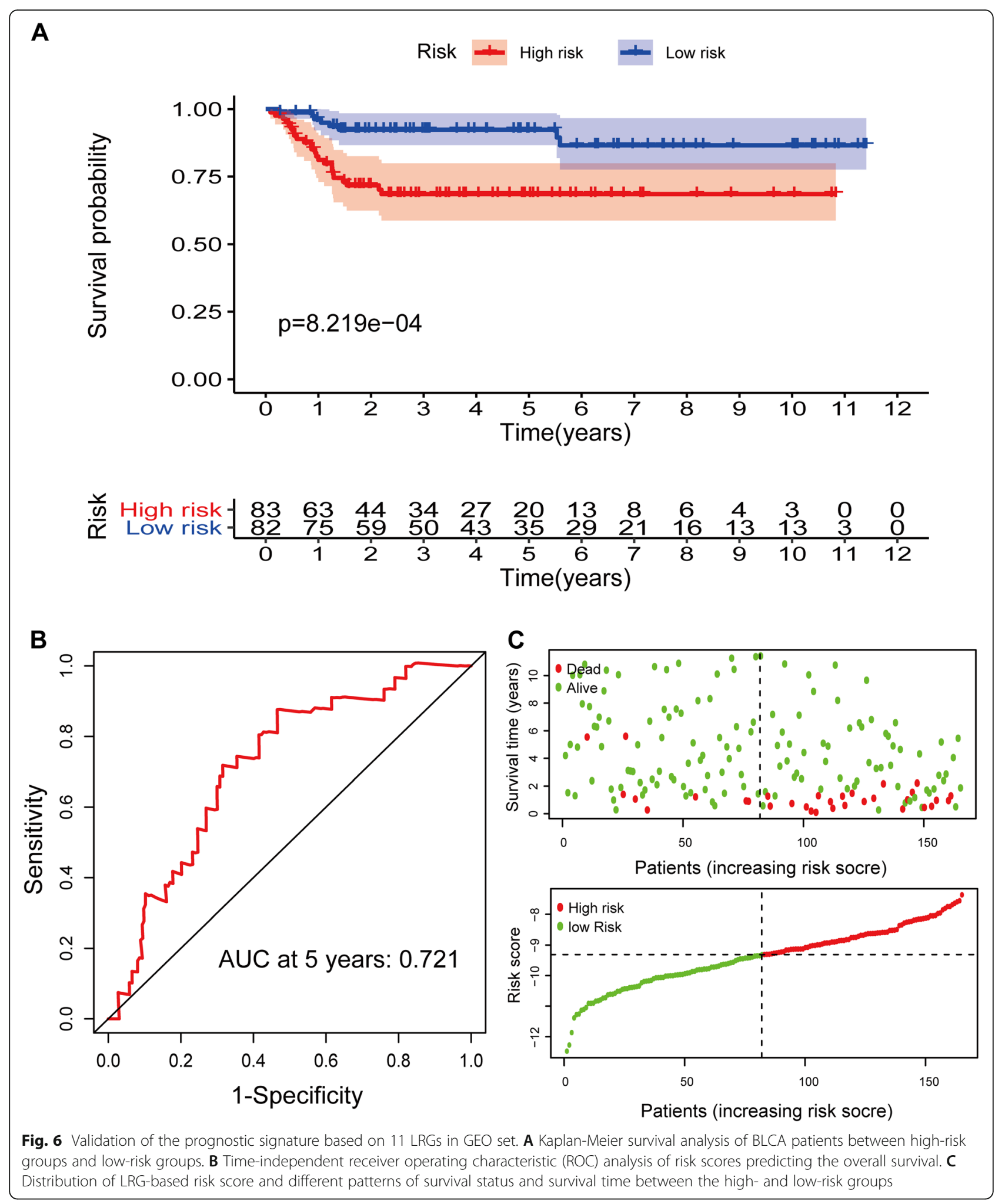

1.783, $95 \% \mathrm{CI}=1.44-2.207, P<0.001), \mathrm{T}$ stage $(\mathrm{HR}=$ $1.569,95 \% \mathrm{CI}=1.233-1.819, P<0.001), \mathrm{N}$ stage $(\mathrm{HR}=$ $1.548,95 \% \mathrm{CI}=1.317-1.819, P<0.001)$, and risk score $(\mathrm{HR}=1.615, \quad 95 \% \quad \mathrm{CI}=1.424-1.832, \quad P<0.001) \quad$ were significantly associated with OS in the univariate analysis (Fig. 10A). Multivariate analysis suggested that age $(\mathrm{HR}=$ $1.032,95 \% \mathrm{CI}=1.014-1.05, P<0.001)$ and risk score $(\mathrm{HR}=$ $1.479, \quad 95 \% \quad \mathrm{CI}=1.298-1.685, \quad P<0.001) \quad$ were also 

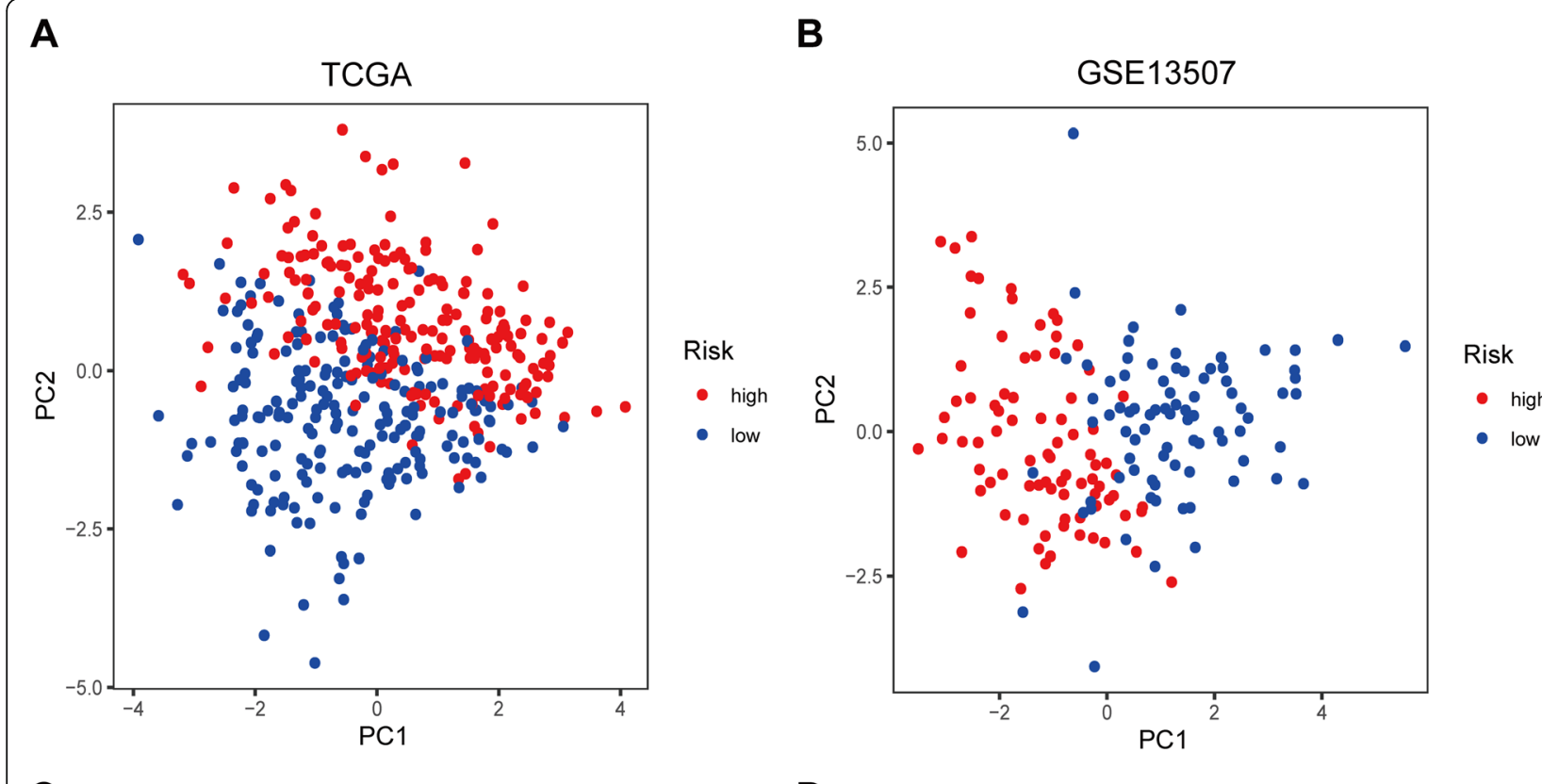

C

D
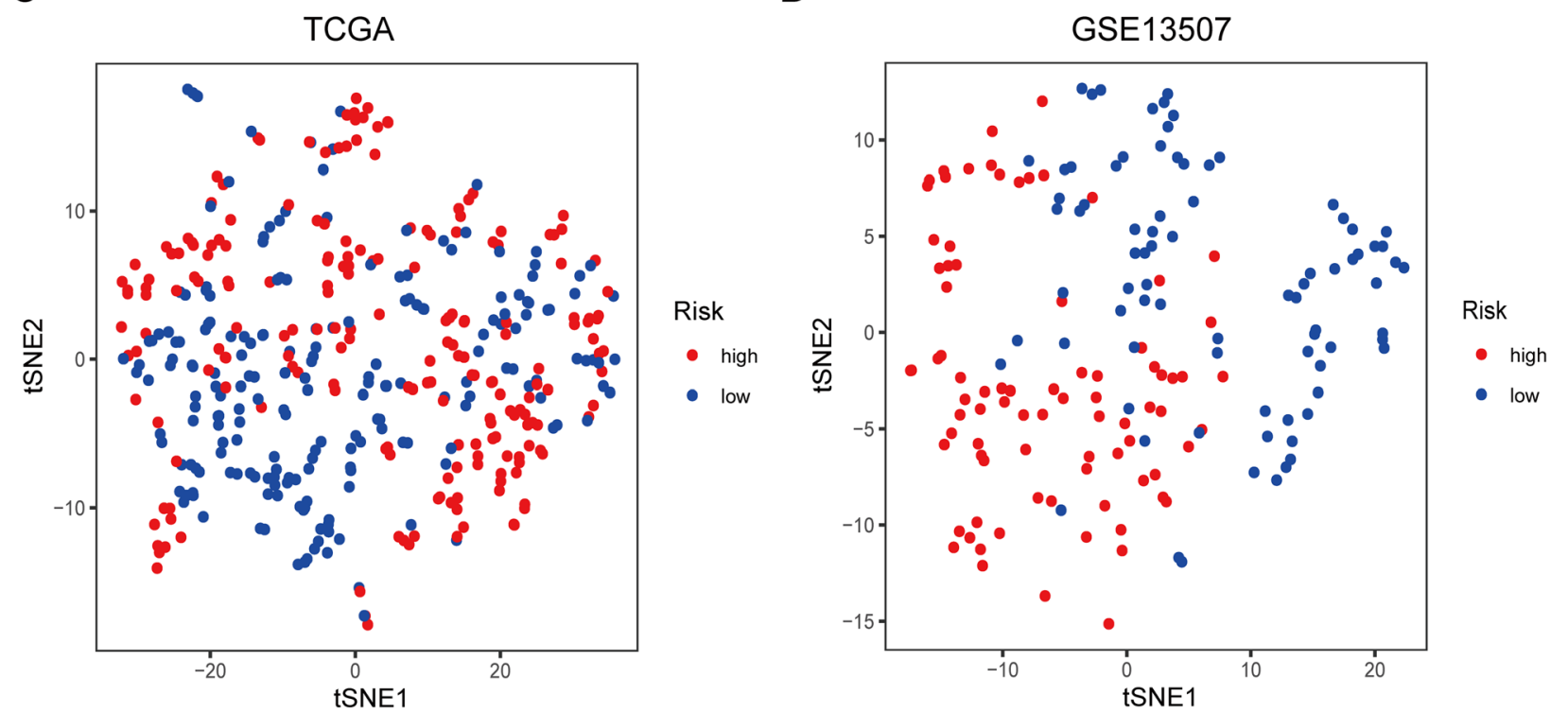

Fig. 7 PCA and t-SNE analysis. A PCA analysis in the TCGA set. B PCA analysis in the GEO set. C t-SNE analysis in the TCGA set. D t-SNE analysis in the GEO set

significantly associated with OS (Fig. 10B). Therefore, this result indicated that the risk score was an independent prognostic predictor. The result of multivariate ROC analysis showed that risk scores displayed a much more favorable performance in predicting OS than traditional pathological prognostic factors (Fig. 10C).

\section{Construction of a nomogram}

To better forecast the prognosis of BLCA patients, a nomogram consisting of the variables (age and risk scores) associated with OS was constructed (Fig. 11A).
The calibration curve suggested that the nomogram showed good performance consistent with the nomogram's 3- or 5-year OS estimates and the KaplanMeier estimates (Fig. 11B and C).

\section{Analysis of immune cells infiltration}

The heatmap of immune responses based on CIBERSORT, QUANTISEQ, MCPcounter, XCELL, CIBERSORT-ABS, TIMER and EPIC algorithms is shown in Fig. 12A, which indicated that risk scores were correlated with immune cell infiltration in BLCA. The CIBERSORT 


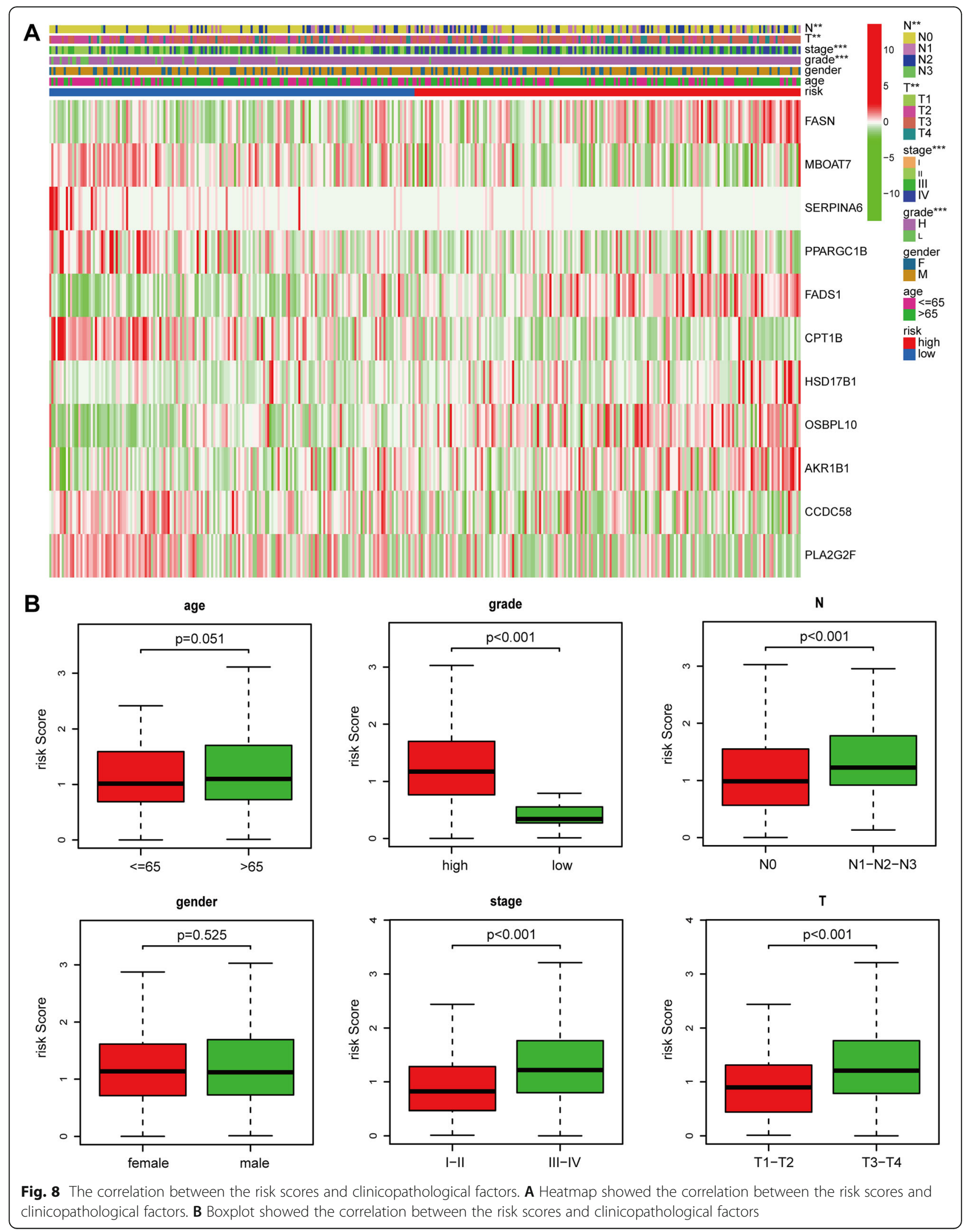




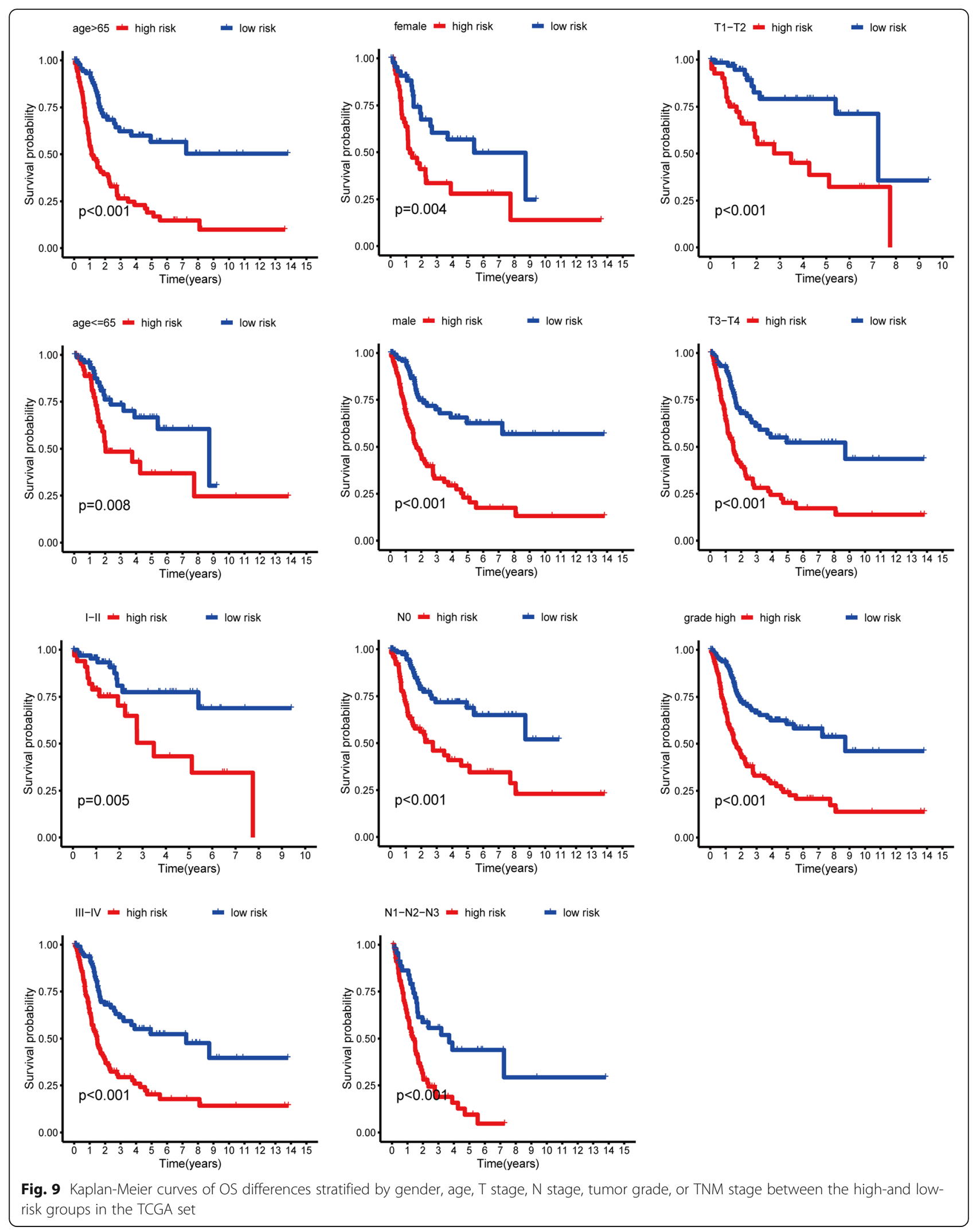




\begin{tabular}{|c|c|c|}
\hline A & pvalue & Hazard ratio \\
\hline age & $<0.001$ & $1.037(1.020-1.055)$ \\
\hline gender & 0.377 & $0.857(0.609-1.207)$ \\
\hline grade & 0.138 & $.443(0.620-31.859)$ \\
\hline stage & $<0.001$ & $1.783(1.440-2.207)$ \\
\hline $\mathrm{T}$ & $<0.001$ & $1.569(1.233-1.998)$ \\
\hline $\mathrm{N}$ & $<0.001$ & $1.548(1.317-1.819)$ \\
\hline riskScore & $<0.001$ & $1.615(1.424-1.832)$ \\
\hline B & pvalue & Hazard ratio \\
\hline age & $<0.001$ & $1.032(1.014-1.050)$ \\
\hline gender & 0.209 & $0.800(0.566-1.133)$ \\
\hline grade & 0.869 & $1.183(0.160-8.776)$ \\
\hline stage & 0.366 & $1.192(0.814-1.746)$ \\
\hline $\mathrm{T}$ & 0.052 & $1.344(0.998-1.811)$ \\
\hline $\mathrm{N}$ & 0.165 & $1.217(0.922-1.607)$ \\
\hline riskScore & $<0.001$ & $1.479(1.298-1.685)$ \\
\hline
\end{tabular}

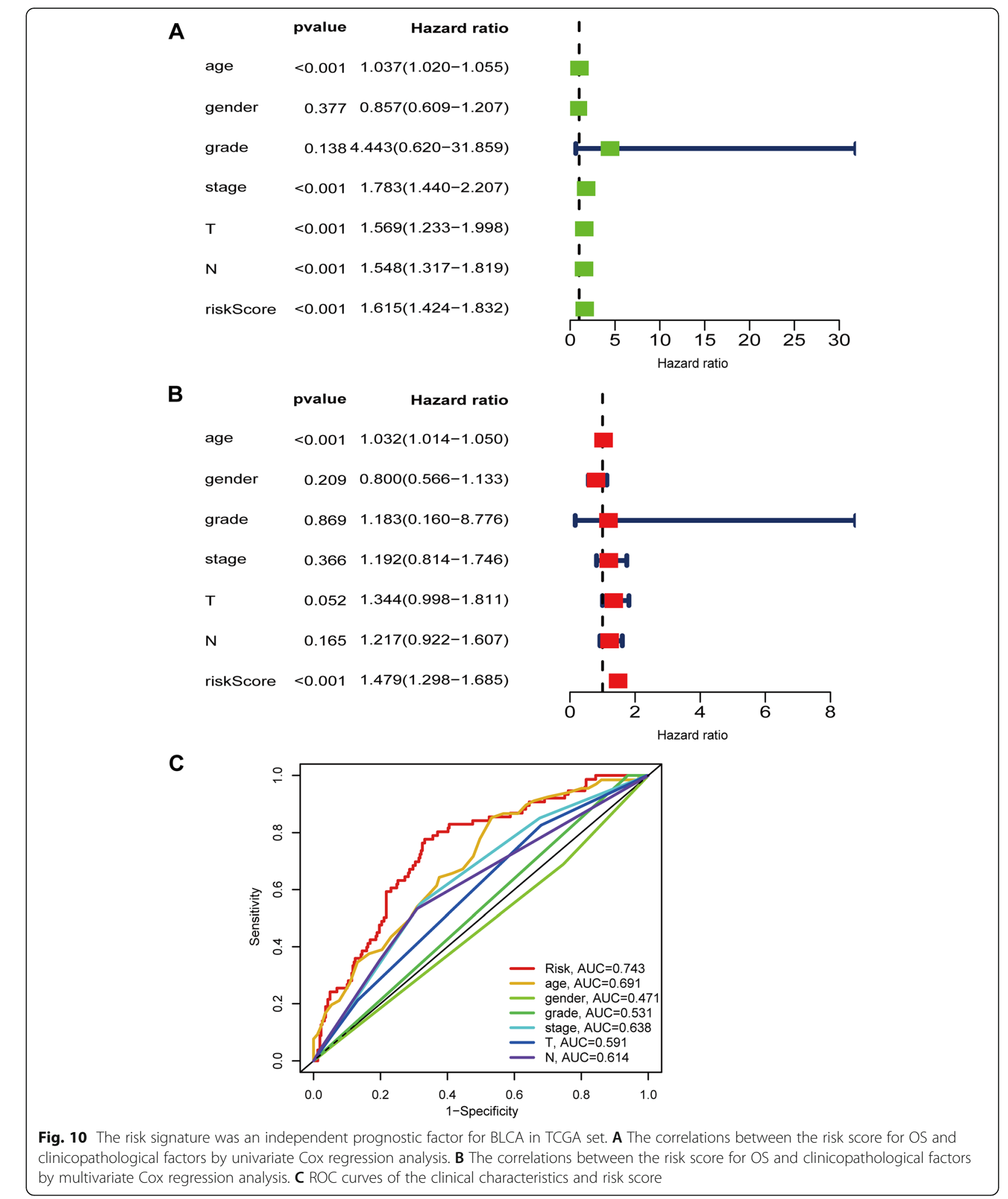

results showed that risk scores were negatively related to the Treg cells and dendritic cell activation (Fig. 12B). In addition, the correlation between risk scores and key immune checkpoint genes (PDCD1, PD-L1, HAVCR2, LAG3 and CTLA4) was also explored. The results showed that the expressions of 


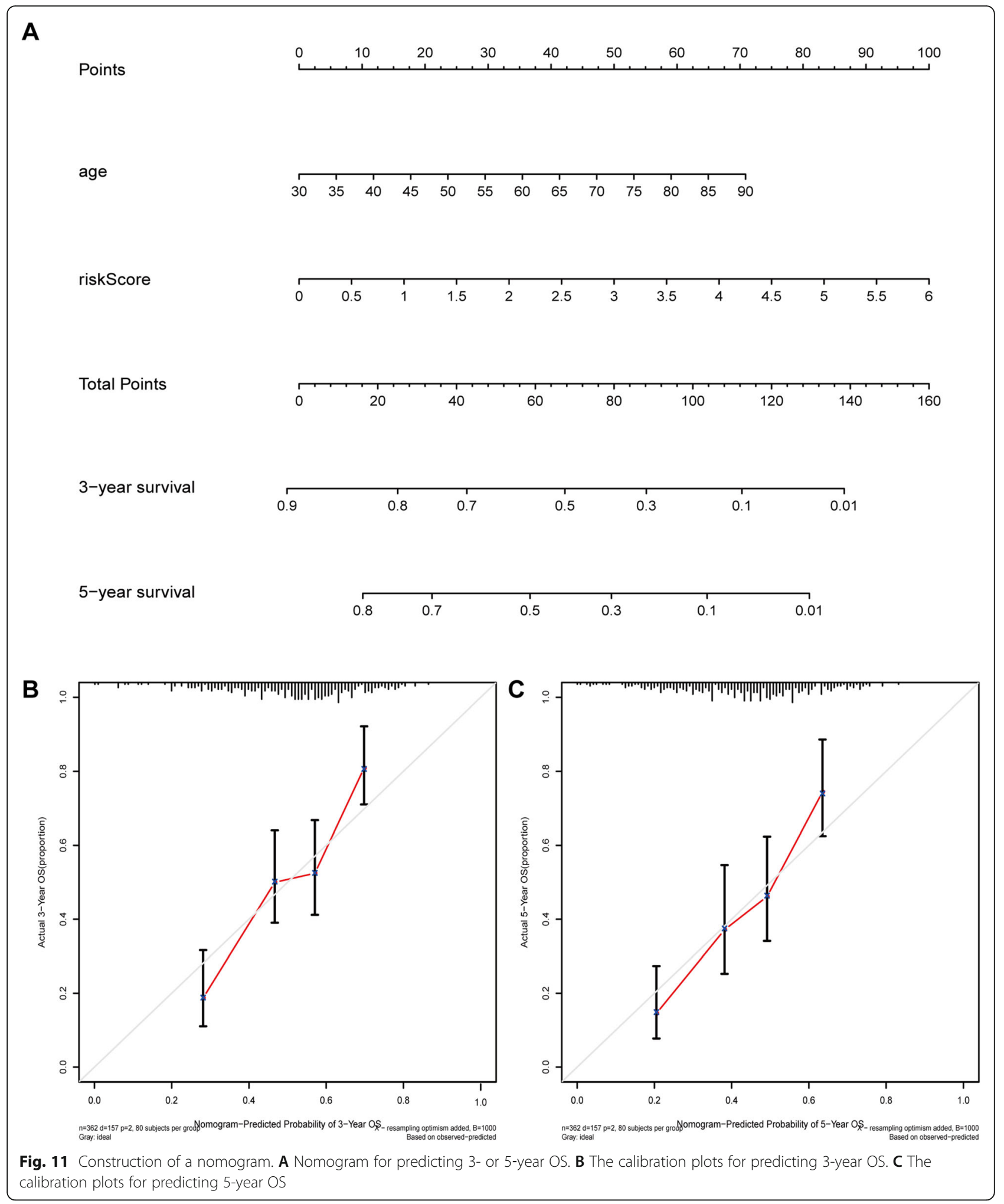

PDCD1, CTLA4, HAVCR2, PD-L1, and LAG3 were elevated in the high-risk groups (Fig. 12C), which suggested an immunosuppressive status in the highrisk groups.

\section{HPA database analysis}

HPA database was performed to explore the protein expression of 11 LRGs by assessing immunohistochemistry staining. HPA database has not included the protein 


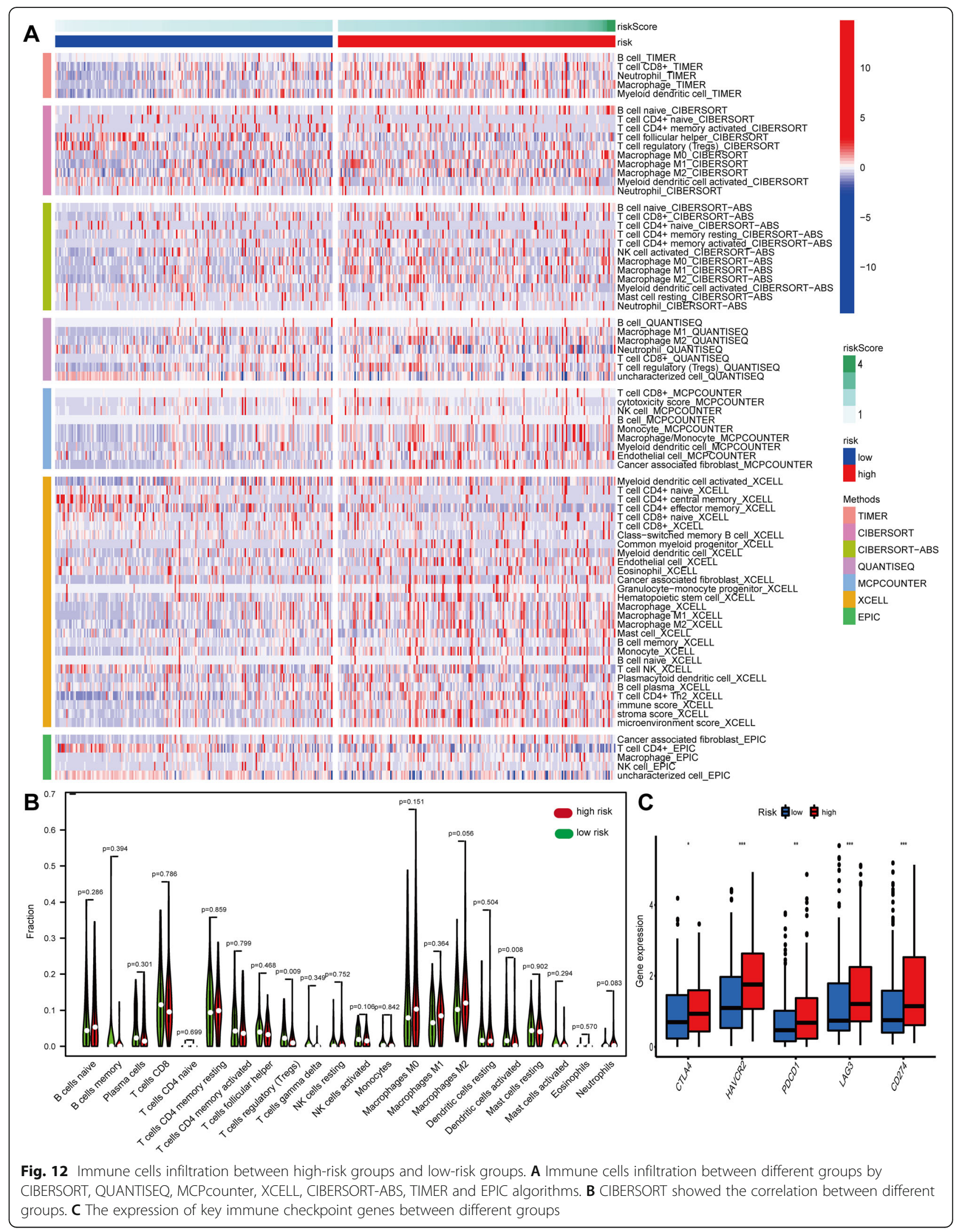


expressions of OSBPL10, PLA2G2F, and PPARGC1B. Compared to the normal bladder tissues, the protein expressions of FASN, MBOA7, SERPINA6, FADS1, AKR1B1, and CCDC58 were obviously elevated in BLCA (Fig. 13). However, the protein expressions of HSD17B1 and CPT1B have no statistical criteria.

\section{Discussion}

Significant advances in BLCA diagnosis and treatment have been achieved over the past two decades. However, the morbidity and mortality of BLCA remain unchanged owing to the aging of the population and absence of specific therapy. Consequently, novel prognostic biomarkers and treatments for BLCA need to be identified to improve patient prognosis. Accumulating studies have suggested that lipid metabolism dysregulation was involved in development and progression of various cancers, including lung cancer [18], prostate cancer [19], gastric carcinoma [20], and BLCA [13]. Despite the crucial role of lipid metabolism in BLCA, studies about the relationship between lipid metabolism and BLCA prognosis are rare.

In the present study, the potential mechanism and prognostic value of LRGs in BLCA were comprehensively investigated through bioinformatic analyses. 113 DELRGs were acquired by analyzing the expression of

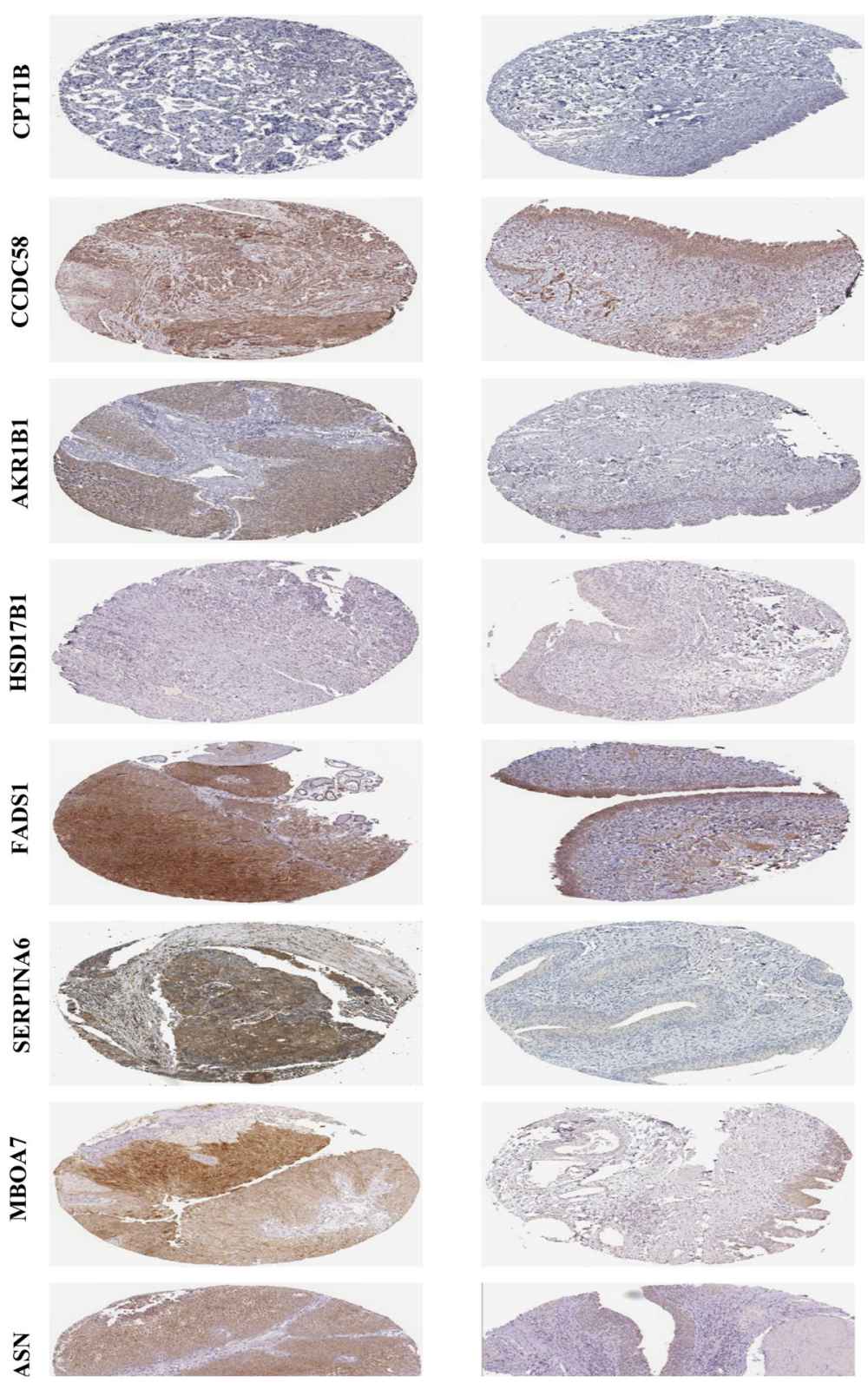

Fig. 13 The protein expression of 11 prognostic genes by HPA database 
LRGs in BLCA tissues compared with normal bladder tissues in TCGA dataset. Then, PPI network and functional enrichment analyses were conducted to investigate the biological function of DELRGs in BLCA. GO and KEGG analyses showed that DELRGs were implicated in steroid metabolic process, fatty acid metabolic process, glycerophospholipid metabolism, PPAR signaling pathway, fatty acid metabolism, and AMPK signaling pathway. Finally, we utilized TCGA cohort to establish a prognostic risk signature and validated its high reliability and stability with GEO cohort. In addition, LRG-based signature was tightly related to inferior clinical characteristics, including TNM stage, $\mathrm{T}$ stage, $\mathrm{N}$ stage, and grade. Subgroups analyses also showed that patients with low risk scores had better outcomes than those with high risk scores. The results of univariate and multivariate analysis indicated that LRG-based signature was an independent prognostic factor in BLCA. Furthermore, multivariate ROC analysis also confirmed that risk scores were much more accurate in predicting OS than traditional pathological prognostic factors. Nomogram analysis indicated that the prognostic signature could be used to predict the outcomes of BLCA patients.

Increasing evidence has confirmed that immune cell infiltration was strongly associated with the development, progression and prognosis as well as the treatment of BLCA. In addition, metabolic remodeling could influence the functions of immune cell. Therefore, the relationship between the risk scores and immune cells infiltration was investigated. The results showed that Treg cells and dendritic cell activation has significantly elevated in the low-risk group compared with the high-risk group. Tregs could promote tumor progression by suppressing effective antitumor immunity and reduce immunotherapy benefits. Patients with BLCA in the high-risk groups had higher expression of PD1, CTLA4 PD-L1, HAVCR2 and LAG3 than those in the low-risk groups, suggesting that the unfavorable prognosis of patients in the high-risk groups might be partly due to the immunosuppressive environment and elevated expression of immune checkpoint genes. Furthermore, our results also suggested that patients in high-risk groups might benefit from immunotherapy.

Fatty acid desaturase 1 (FADS1), located on chromosome 11q12-11q13.1, is a member of the fatty acid desaturase gene family. Studies on FADS1 have primarily focused on its polymorphisms and deem FADS1 a rate-limiting enzyme in the biosynthesis of long-chain polyunsaturated fatty acid precursors of eicosanoids [21]. FADS1 has been reported to play a crucial role in many diseases, including type-1 diabetes and cancer [22, 23]. FADS1 can promote the progression of laryngeal squamous cell carcinoma by activating the AKT/mTOR signaling pathway [24]. Reduced FADS1 expression has been related to poor prognosis in NSCLC patients [22]. Jiao reported that FADS1 overexpression was positively correlated with tumor grade in BLCA [25]. Further study indicated that FADS1 knockdown inhibited BLCA cell proliferation by arresting the cell cycle. Membrane bound O-acyltransferase domain containing 7 (MBOAT7) has been reported to play an important role in inflammation [26]. Heinrichs found that MBOAT7 might contribute to GC susceptibility through inflammation [27]. MBOAT7 was overexpressed in renal cancer cells and high MBOAT7 expression was associated with poor prognosis in ccRCC [28].CCDC58 may play a tumorpromoting role in endometrial cancer. Aldo-keto reductase 1 member B1 (AKR1B1) could be involved in various signaling pathways, such as epithelial to mesenchymal transition (EMT) [29], inflammatory responses [30], and the mTOR pathway [31]. An increasing numbers of studies have suggested that AKR1B was involved in cancer progression [32]. Carnitine palmitoyltransferase 1B (CPT1B) has been reported to be correlated with tumor proliferation and metastasis by regulating EMT in BLCA [33]. Overexpression of CPT1B was correlated with worse OS in prostate cancer [34]. Further study revealed that AR-mediated CPT1B promoted castration-sensitive and castration-resistant prostate cancer (CRPC) progression by upregulating AKT expression and phosphorylation. Peroxisome proliferator-activated receptor gamma coactivator 1 beta (PPARGC1B) could increase its transcriptional activity by selectively interacting with $\mathrm{ERa}$, which plays a vital role in the ER signaling pathway [35]. PPARGC1B could inhibit miR-21 mediated fatty acid metabolism [36]. SERPINA6 is related to chemotherapy resistance in breast cancer [37].

Furthermore, CMAP dataset was used to identify five potential small molecule drugs highly related to LRGs for the treatment of BLCA patients. Flurbiprofen, a nonselective cyclooxygenase suppressor, is commonly used to control inflammation and pain during surgery. Recently, flurbiprofen has been reported to exert anticancer effects via suppressing proliferation and inducing apoptosis in several tumors [38, 39]. Meclizine could inhibit breast cancer cell clonogenesis in vitro [40]. Alfuzosin, an alpha1-adrenergic receptor antagonist, that is widely generally used for the treatment of hypertension and benign prostatic hyperplasia, reduced the growth of $\mathrm{PC} 3$ prostate tumor cells. Fenoprofen, a nonsteroidal antiinflammatory drug, has been reported to be related to the incidence and metastases of prostate cancer [41]. Further research has shown that fenoprofen decreased the survival of prostate cancer cells by upregulating the expression of p75NTR (a neurotrophin receptor).

\section{Study strengths and limitations}

The major strength of this study is the construction and validation of a prognostic signature based on lipid metabolism-related genes that is closely related to prognosis of BLCA patients. The main limitation of the study 
is the absence of experimental validation in vivo and vitro. Therefore, further experiments should be performed to validate the functions of lipid metabolismrelated genes in BLCA.

\section{Conclusions}

In conclusion, the expression, prognostic value, and function of lipid metabolism-related genes in BLCA were investigated by comprehensive bioinformatic analyses. A novel prognostic signature comprising 11 genes involved in lipid metabolism for predicting the outcomes of patients with BLCA was established and validated. In addition, the prognostic signature could serve as an indicator for predicting the therapeutic effect of immunotherapy in BLCA.

\section{Abbreviations}

BLCA: Bladder cancer; LRGs: Lipid metabolism-related genes;

MSigDB: Molecular Signature Database; DELRGs: Differentially expressed lipid metabolism-related genes; TCGA: The Cancer Genome Atlas; GEO: Gene Expression Omnibus; KEGG: Kyoto Encyclopedia of Genes and Genomes; FDR: False discovery rate; FC: Fold change; GO: Gene ontology

\section{Supplementary Information}

The online version contains supplementary material available at https://doi. org/10.1186/s12944-021-01554-1.

\section{Additional file 1}

\section{Acknowledgements}

Not applicable.

\section{Authors' contributions}

$K Z$, LX and WD designed the research study. LX and WD took responsibility for statistical analyses. KZ wrote the manuscript. WG and BF evaluated and revised the manuscript. All authors read and approved the final manuscript.

\section{Funding}

This work was supported by grants from the National Natural Science Foundation of China (No: 81960512).

\section{Availability of data and materials}

The raw data of this study are derived from the TCGA database (https:// portal.gdc.cancer.gov/) and GEO data portal (https://www.ncbi.nlm.nih.gov/ geo/), which are publicly available databases.

\section{Declarations}

Ethics approval and consent to participate

Not applicable.

\section{Consent for publication}

Not applicable.

\section{Competing interests}

No competing interests.

\section{Author details}

1Present address: Department of Urology, The First Affiliated Hospital of Nanchang University, 17 Yongwaizheng Street, Jiangxi 330006 Nanchang, People's Republic of China. ${ }^{2}$ Jiangxi Institute of Urology, Jiangxi 330006 Nanchang, People's Republic of China.
Received: 28 July 2021 Accepted: 10 September 2021

Published online: 27 October 2021

\section{References}

1. Sung H, Ferlay J, Siegel RL, Laversanne M, Soerjomataram I, Jemal A, Bray F. Global Cancer Statistics 2020: GLOBOCAN estimates of incidence and mortality worldwide for 36 cancers in 185 countries. CA Cancer J Clin. 2021; 71:209-49. https://doi.org/10.3322/caac.21660.

2. Freedman ND, Silverman DT, Hollenbeck AR, Schatzkin A, Abnet CC. Association between smoking and risk of bladder cancer among men and women. JAMA J Am Med Assoc. 2011;306:737-45. https://doi.org/10.1001/ja ma.2011.1142

3. Hamaidi I, Zhang L, Kim N, Wang M-H, Iclozan C, Fang B, Liu M, Koomen $J M$, Berglund AE, Yoder SJ, et al. Sirt2 inhibition enhances metabolic fitness and effector functions of tumor-reactive T cells. Cell Metab. 2020;32:420-36. e12. https://doi.org/10.1016/j.cmet.2020.07.008.

4. Liu J, Peng Y, Shi L, Wan L, Inuzuka H, Long J, Guo J, Zhang J, Yuan M, Zhang S, et al. Skp2 dictates cell cycle-dependent metabolic oscillation between glycolysis and TCA cycle. Cell Res. 2021;31:80-93. https://doi.org/1 0.1038/s41422-020-0372-z.

5. Sun X, Zhan L, Chen Y, Wang G, He L, Wang Q, Zhou F, Yang F, Wu J, Wu Y, et al. Increased MtDNA copy number promotes cancer progression by enhancing mitochondrial oxidative phosphorylation in microsatellite-stable colorectal cancer. Signal Transduct Target Ther. 2018;3:8. https://doi.org/10.1 038/s41392-018-0011-z.

6. Li T, Han J, Jia L, Hu X, Chen L, Wang Y. PKM2 coordinates glycolysis with mitochondrial fusion and oxidative phosphorylation. Protein Cell. 2019;10: 583-94. https://doi.org/10.1007/s13238-019-0618-z.

7. Olmstead AD, Knecht W, Lazarov I, Dixit SB, Jean F, Human Subtilase. SKI-1/ S1P is a master regulator of the HCV lifecycle and a potential host cell target for developing indirect-acting antiviral agents. PLoS Pathog. 2012;8: e1002468. https://doi.org/10.1371/journal.ppat.1002468.

8. Butler LM, Perone Y, Dehairs J, Lupien LE, de Laat V, Talebi A, Loda M, Kinlaw WB, Swinnen JV. Lipids and cancer: emerging roles in pathogenesis, diagnosis and therapeutic intervention. Adv Drug Deliv Rev. 2020;159:24593. https://doi.org/10.1016/j.addr.2020.07.013.

9. Khatua B, El-Kurdi B, Patel K, Rood C, Noel P, Crowell M, Yaron JR, Kostenko $\mathrm{S}$, Guerra A, Faigel DO, et al. Adipose saturation reduces lipotoxic systemic inflammation and explains the obesity paradox. Sci Adv. 2021;7:eabd6449. https://doi.org/10.1126/sciadv.abd6449.

10. Röhrig F, Schulze A. The multifaceted roles of fatty acid synthesis in cancer. Nat Rev Cancer. 2016;16:732-49. https://doi.org/10.1038/nrc.2016.89.

11. Snaebjornsson MT, Janaki-Raman S, Schulze A. Greasing the wheels of the cancer machine: the role of lipid metabolism in cancer. Cell Metab. 2020;31: 62-76. https://doi.org/10.1016/j.cmet.2019.11.010.

12. Peng T, Wang G, Cheng S, Xiong Y, Cao R, Qian K, Ju L, Wang X, Xiao Y. The role and function of PPARY in bladder cancer. J Cancer. 2020;11:3965-75. https://doi.org/10.7150/jca.42663.

13. Cheng S, Wang G, Wang Y, Cai L, Qian K, Ju L, Liu X, Xiao Y, Wang X. Fatty acid oxidation inhibitor etomoxir suppresses tumor progression and induces cell cycle arrest via PPARy-mediated pathway in bladder cancer. Clin Sci. 2019;133:1745-58. https://doi.org/10.1042/CS20190587.

14. Chao H, Deng L, Xu F, Yu Z, Xu X, Huang J, Zeng T. MEX3C regulates lipid metabolism to promote bladder tumorigenesis through JNK pathway. OncoTargets Ther. 2019;12:3285-94. https://doi.org/10.2147/OTT.S199667.

15. Abdelrahman AE, Rashed HE, Elkady E, Elsebai EA, El-Azony A, Matar I. Fatty acid synthase, Her2/Neu, and E2F1 as prognostic markers of progression in non-muscle invasive bladder cancer. Ann Diagn Pathol. 2019;39:42-52. https://doi.org/10.1016/j.anndiagpath.2019.01.002.

16. Zheng S-S, Gao J-G, Liu Z-J, Zhang X-H, Wu S, Weng B-W, Wang Y-L, Hou SC, Jiang B. Downregulation of fatty acid synthase complex suppresses cell migration by targeting phospho-AKT in bladder cancer. Mol Med Rep. 2016; 13:1845-50. https://doi.org/10.3892/mmr.2015.4746.

17. Shahid M, Kim M, Jin P, Zhou B, Wang Y, Yang W, You S, Kim J. Spalmitoylation as a functional regulator of proteins associated with cisplatin resistance in bladder cancer. Int J Biol Sci. 2020;16:2490-505. https://doi. org/10.7150/ijbs.45640.

18. Sun Z, Jiang Q, Li J, Guo J. The potent roles of Salt-Inducible Kinases (SIKs) in metabolic homeostasis and tumorigenesis. Signal Transduct Target Ther. 2020;5:150. https://doi.org/10.1038/s41392-020-00265-w. 
19. Liu R-Z, Godbout R. An amplified fatty acid-binding protein gene cluster in prostate cancer: emerging roles in lipid metabolism and metastasis. Cancers. 2020;12:3823. https://doi.org/10.3390/cancers12123823.

20. Huang S, Guo Y, Li Z, Zhang Y, Zhou T, You W, Pan K, Li WA. Systematic review of metabolomic profiling of gastric cancer and esophageal cancer. Cancer Biol Med. 2020;17:181-98. https://doi.org/10.20892/j.issn.2095-3941.2 019.0348 .

21. Lopes-Marques M, Kabeya N, Qian Y, Ruivo R, Santos MM, Venkatesh B, Tocher DR, Castro LFC, Monroig Ó. Retention of Fatty Acyl Desaturase 1 (Fads1) in elopomorpha and cyclostomata provides novel insights into the evolution of long-chain polyunsaturated fatty acid biosynthesis in vertebrates. BMC Evol Biol. 2018;18:157. https://doi.org/10.1186/s12862-01 8-1271-5.

22. Wang D, Lin Y, Gao B, Yan S, Wu H, Li Y, Wu Q, Wei Y. Reduced expression of FADS1 predicts worse prognosis in non-small-cell lung cancer. J Cancer. 2016;7:1226-32. https://doi.org/10.7150/jca.15403.

23. Huang M-C, Chang W-T, Chang H-Y, Chung H-F, Chen F-P, Huang Y-F, Hsu C-C, Hwang S-J. FADS gene polymorphisms, fatty acid desaturase activities, and HDL-C in type 2 diabetes. Int J Environ Res Public Health. 2017;14:572 https://doi.org/10.3390/ijerph14060572.

24. Zhao R, Tian L, Zhao B, Sun Y, Cao J, Chen K, Li F, Li M, Shang D, Liu M. FADS1 promotes the progression of laryngeal squamous cell carcinoma through activating AKT/MTOR signaling. Cell Death Dis. 2020;11:272. https:// doi.org/10.1038/s41419-020-2457-5.

25. Jiao F, Sun $H$, Yang Q, Sun H, Wang Z, Liu M, Chen J. Identification of FADS1 through common gene expression profiles for predicting survival in patients with bladder cancer. Cancer Manag Res. 2020;12:8325-39. https:// doi.org/10.2147/CMAR.S254316.

26. Thabet K, Asimakopoulos A, Shojaei M, Romero-Gomez M, Mangia A, Irving WL, Berg T, Dore GJ, Grønbæk H, Sheridan D, et al. MBOAT7 Rs641738 increases risk of liver inflammation and transition to fibrosis in chronic hepatitis C. Nat Commun. 2016;7:12757. https://doi.org/10.1038/ncomms12 757.

27. Heinrichs SKM, Hess T, Becker J, Hamann L, Vashist YK, Butterbach K, Schmidt T, Alakus H, Krasniuk I, Höblinger A, et al. Evidence for PTGE R4,PSCA, and MBOAT7 as risk genes for gastric cancer on the genome and transcriptome level. Cancer Med. 2018;7:5057-65. https://doi.org/10.1002/ca m4.1719.

28. Neumann CKA, Silver DJ, Venkateshwari V, Zhang R, Traughber CA, Przybycin C, Bayik D, Smith JD, Lathia JD, Rini BI, et al. MBOAT7-driven phosphatidylinositol remodeling promotes the progression of clear cell renal carcinoma. Mol Metab. 2020;34:136-45. https://doi.org/10.1016/j. molmet.2020.01.011.

29. Wu X, Li X, Fu Q, Cao Q, Chen X, Wang M, Yu J, Long J, Yao J, Liu H, et al. AKR1B1 promotes basal-like breast cancer progression by a positive feedback loop that activates the EMT program. J Exp Med. 2017;214:106579. https://doi.org/10.1084/jem.20160903.

30. Chen X, Chen C, Hao J, Qin R, Qian B, Yang K, Zhang J, Zhang F. AKR1B1 upregulation contributes to neuroinflammation and astrocytes proliferation by regulating the energy metabolism in rat spinal cord injury. Neurochem Res. 2018:43:1491-9. https://doi.org/10.1007/s11064-018-2570-3.

31. Pal PB, Sonowal H, Shukla K, Srivastava SK, Ramana KV. Aldose reductase regulates hyperglycemia-induced HUVEC death via SIRT1/AMPK-A1/MTOR pathway. J Mol Endocrinol. 2019;63:11-25. https://doi.org/10.1530/JME-190080 .

32. Khayami R, Hashemi SR, Kerachian MA. Role of aldo-keto reductase family 1 member B1 (AKR1B1) in the cancer process and its therapeutic potential. J Cell Mol Med. 2020;24:8890-902. https://doi.org/10.1111/jcmm.15581.

33. Vantaku V, Dong J, Ambati CR, Perera D, Donepudi SR, Amara CS, Putluri V, Shiva Shankar R, Robertson MJ, Piyarathna DWB, et al. Multi-omics integration analysis robustly predicts high-grade patient survival and identifies CPT1B effect on fatty acid metabolism in bladder cancer. Clin Cancer Res Off J Am Assoc Cancer Res. 2019;25:3689-701. https://doi.org/1 0.1158/1078-0432.CCR-18-1515.

34. Abudurexiti M, Zhu W, Wang Y, Wang J, Xu W, Huang Y, Zhu Y, Shi G, Zhang $\mathrm{H}$, Zhu $Y$, et al. Targeting CPT1B as a potential therapeutic strategy in castration-resistant and enzalutamide-resistant prostate cancer. Prostate. 2020;80:950-61. https://doi.org/10.1002/pros.24027.

35. Chang HS, Lee S-H, Lee J-U, Park JS, Chung IY, Park C-S. Functional characterization of exonic variants of the PPARGCIB gene in coregulation of estrogen receptor alpha. DNA Cell Biol. 2016;35:314-21. https://doi.org/10.1 089/dna.2015.3195.

36. Ni K, Wang D, Xu H, Mei F, Wu C, Liu Z, Zhou B. MiR-21 promotes non-small cell lung cancer cells growth by regulating fatty acid metabolism. Cancer Cell Int. 2019;19:219. https://doi.org/10.1186/s12935-019-0941-8.

37. de Ronde JJ, Lips EH, Mulder L, Vincent AD, Wesseling J, Nieuwland M, Kerkhoven R, Vrancken Peeters M-JTFD, Sonke GS, Rodenhuis S, et al. SERPINA6, BEX1, AGTR1, SLC26A3, and LAPTM4B are markers of resistance to neoadjuvant chemotherapy in HER2-negative breast cancer. Breast Cancer Res Treat. 2013;137:213-23. https://doi.org/10.1007/s10549-012-2340-x.

38. Ooki A, Del Carmen Rodriguez Pena M, Marchionni L, Dinalankara W, Begum A, Hahn NM, VandenBussche CJ, Rasheed ZA, Mao S, Netto GJ, et al. YAP1 and COX2 coordinately regulate urothelial cancer stem-like cells. Cancer Res. 2018;78:168-81. https://doi.org/10.1158/0008-5472.CAN-17-0836.

39. Yin $Y$, Yi Y, Yu J, Sun $X$, Liu C, Xu F. Effects of flurbiprofen on serum level of interleukin-6, prostacyclin and corticosteroid A2 in patients with bone metastases of cancer. Oncol Lett. 2018;15:1545-8. https://doi.org/10.3892/ ol.2017.7482.

40. Christov K, Grubbs CJ, Shilkaitis A, Juliana MM, Lubet RA. Short-term modulation of cell proliferation and apoptosis and preventive/therapeutic efficacy of various agents in a mammary cancer model. Clin Cancer Res. 2007:13:5488-96. https://doi.org/10.1158/1078-0432.CCR-07-0404.

41. Quann EJ, Khwaja F, Zavitz KH, Djakiew D. The aryl propionic acid $R$ -flurbiprofen selectively induces P75 NTR -dependent decreased survival of prostate tumor cells. Cancer Res. 2007;67:3254-62. https://doi.org/10.1158/ 0008-5472.CAN-06-3657.

\section{Publisher's Note}

Springer Nature remains neutral with regard to jurisdictional claims in published maps and institutional affiliations.

\section{Ready to submit your research? Choose BMC and benefit from:}

- fast, convenient online submission

- thorough peer review by experienced researchers in your field

- rapid publication on acceptance

- support for research data, including large and complex data types

- gold Open Access which fosters wider collaboration and increased citations

- maximum visibility for your research: over $100 \mathrm{M}$ website views per year

At BMC, research is always in progress.

Learn more biomedcentral.com/submissions 